\title{
Adsorption of Anionic Dye Onto ZSM-5 Zeolite- based Bio Membrane: Characterizations, Kinetics and Adsorption Isotherm
}

\author{
Sabarish Radoor ( $\sim$ sabarishchem@gmail.com ) \\ King Mongkut's University of Technology North Bangkok \\ Jasila Karayil \\ Government Women's Polytechnic College
}

Aswathy Jayakumar

King Mongkut's University of Technology North Bangkok

Jyotishkumar Parameswaranpillai

Mar Athanasios College for Advanced Studies Tiruvalla

Jaewoo Lee

Jeonbuk: Jeonbuk National University

Jyothi Mannekote Shivanna

AMC Engineering College

Rajarathinam Nithya

Government College of Technology

Suchart Siengchin

King Mongkut's University of Technology North Bangkok

\section{Research Article}

Keywords: ZSM-5 zeolite, Gelatin, Carboxymethyl cellulose, Adsorption, Rhodamine B

Posted Date: January 3rd, 2022

DOI: https://doi.org/10.21203/rs.3.rs-1191111/v1

License: (1) (1) This work is licensed under a Creative Commons Attribution 4.0 International License.

Read Full License 


\title{
Adsorption of anionic dye onto ZSM-5 zeolite-based bio membrane: Characterizations, kinetics and adsorption isotherm
}

\author{
Sabarish Radoor ${ }^{1 *}$, Jasila Karayil ${ }^{2}$, Aswathy Jayakumar ${ }^{1}$, Jyotishkumar \\ Parameswaranpillai ${ }^{3}$, Jaewoo Lee ${ }^{4,5}$, Jyothi Mannekote Shivanna ${ }^{6}$, Rajarathinam Nithya ${ }^{7}$, \\ Suchart Siengchin ${ }^{1,8^{*}}$
}

1. Materials and Production Engineering, The Sirindhorn International Thai-German Graduate School of Engineering (TGGS), King Mongkut's University of Technology North Bangkok, Bangkok 10800, Thailand

2. Government Women's Polytechnic College, Calicut, Kerala, India

3. School of Biosciences, Mar Athanasios College for Advanced Studies Tiruvalla (MACFAST), Pathanamthitta, Kerala, India

4. Department of Polymer-Nano Science and Technology, Jeonbuk National University, 567 Baekje-daero, Deokjin-gu, Jeonju-si 54896, Korea

5. Department of Bionanotechnology and Bioconvergence Engineering, Jeonbuk National University, 567 Baekje-daero, Deokjin-gu, Jeonju-si 54896, Korea

6. AMC Engineering College, Bannerghatta Main Road, Bengaluru, Karnataka, 560083, India

7. Department of Industrial Biotechnology, Government College of Technology, Coimbature-641027

8. Institute of Plant and Wood Chemistry, Technische Universität Dresden, Pienner Str. 19, Tharandt, 01737, Germany

*Corresponding authors:

Sabarish Radoor, Email: sabarishchem@gmail.com

Suchart Siengchin, Email: suchart.s.pe@tggs-bangkok.org

\section{Abstract}

In this study, we report polyvinyl alcohol/carboxymethyl cellulose/gelatin/ZSM-5 zeolite (PVA/CMC/GEL/ZSM-5) membrane for anionic dye (rhodamine B, Rh B) removal from aqueous solution. The prepared membrane was characterized using different techniques such as Fourier transform infrared spectroscopy (FT-IR), X-ray diffraction (XRD), scanning electron microscopy (SEM), optical microscopy (OM), universal testing machine (UTM) and water contact angle respectively. XRD, FT-IR and SEM analysis indicates successful 
incorporation of zeolite into PVA/CMC/GEL membrane. The improved hydrophobicity of the zeolite loaded membrane was confirmed by contact angle analysis. The $\mathrm{Rh} \mathrm{B}$ removal efficiency of zeolite loaded PVA/CMC/GEL membrane was investigated through batch adsorption technique. The effect of different parameters such as initial dye concentration, zeolite dosage, contact time, temperature and $\mathrm{pH}$ on the adsorption was examined. $\mathrm{Rh} \mathrm{B}$ dye adsorption onto the membrane followed Freundlich isotherm model. The kinetic studies revealed that Rh B dye adsorption on the membrane could be explained using pseudo-secondorder model. Finally, the recyclability test revealed that the membrane exhibits good recycle efficiency and is stable after 6 recycle.

Keywords: ZSM-5 zeolite; Gelatin; Carboxymethyl cellulose; Adsorption; Rhodamine B

\section{Introduction}

Water is a basic resource which is essential for life [1]. Although our planet earth covers $71 \%$ of water, only $2 \%$ of its water is available as pure water $[2,3]$. Due to anthropogenic activity, most of our water bodies get contaminated with dyes, heavy metals, microorganisms etc. [4, 5]. The industries responsible for escalating the chemical contaminant in water are textiles, cosmetics, paper, leather, pharmaceuticals, plastic, paints and varnish [6]. Dyes are one of the major sources of water pollution [7]. Dyes are organic compound which are mainly used to colour textiles, foods etc.[8, 9]. Most of the synthetic dyes are toxic, carcinogenic and mutagenic [10]. High chemically stability, large molecular weight and low biodegradability makes dyes a potent water pollutant. Even at low concentration, dyes can cause serious health issues to human as well as animals $[11,12]$. Therefore, the removal of organic dyes from aqueous solution was extremely important for the environment and its species [13]. Ionexchange, solvent extraction, precipitation, filtration, ozonation, adsorption, evaporation, reverse osmosis, flotation, electrochemical etc. are different techniques which are commonly used for the removal of dye from aqueous solution [14-18]. Adsorption process received special attention from researchers as its simple, cheap, efficient and possess good regeneration ability [19]. Large numbers of adsorbents are available for the removal of contaminants from waste water [20, 21]. Synthetic adsorbents such as carbon, clay, silica etc. have been successfully employed for the removal of both cationic and anionic dye from water [22, 23]. However, high cost and low regeneration capacity of synthetic adsorbent limits its industrial applications [24, 25]. 
Zeolites are naturally occurring aluminosilicate. Here the tetrahedral $\mathrm{TO}_{4}(\mathrm{~T}=\mathrm{Si}, \mathrm{Al})$ unit combine together to form a 3D structure with interconnected channels and voids [26, 27]. Compared with other adsorbents, zeolite possesses some superior properties such as high surface area, porosity, thermal stability, ion-exchange capacity and so on [28, 29]. . These special features make them a unique material for water treatment [30, 31]. Zeolite is a good adsorbent for the removal of heavy metal from aqueous solution [32]. Zeolites based polymer composites have been successfully employed for the removal of toxic contaminants from water [33]. There are few studies on the removal of toxic dyes from wastewater using zeolites.

Habiba et al. [34] developed poly(vinyl alcohol)/chitosan/zeolite composite for the removal of methyl orange, congo red and chromium (VI) from wastewater. The authors observed that zeolite incorporated composite has high removal efficiency $(94 \%)$ at an initial dye concentration of $125 \mathrm{mg} / \mathrm{L}$. Therefore, it was suggested as a potential candidate for wastewater treatment. The same group [35] fabricated poly(vinyl alcohol)/chitosan/zeolite composite through electrospinning method. They observed that the addition of zeolite improved the physical and adsorption properties of the membrane. Baberi et al. [36] fabricated PVA/4A zeolite membrane for methylene dye removal from water. They found that the prepared membrane exhibits high adsorption capacity $(9.18 \mathrm{mg} / \mathrm{g})$ towards methylene blue. Another group [37] developed an economical membrane from cellulose/bentonite zeolite. Their studies revealed that $99 \%$ of the brilliant green dye was removed using the composite. The negative charge on the zeolite is responsible for attracting the cationic dye. Zeolite containing both micro and mesopores are termed as hierarchical zeolites and are superior to conventional zeolite. Therefore, in our previous studies we have synthesized hierarchical zeolite and applied it for the development of polymer membranes. Our group have successfully employed PVA/CMC/zeolite for methylene blue dye adsorption from aqueous solution. Maximum removal efficiency (99\%) was achieved at $0.3 \mathrm{~g}$ of zeolite dosage [13]. Due to the electrostatic attraction between the negatively charged dye molecule and positively charged membrane. Similarly, PVA/agar/ZSM-5 zeolite membrane exhibits good Congo red dye removal efficiency $(89 \%)$. The high surface area and porosity of zeolite will enhanced the adsorption capacity PVA/agar membrane [20].

The aim of the present study is to synthesis hierarchical zeolite and employed it for the fabrication of PVA/CMC/GEL membrane for $\mathrm{Rh} \mathrm{B}$ removal from aqueous solution. The polymers used in this study was eco-friendly and non-toxic polymers such as (polyvinyl alcohol) PVA, (carboxymethyl cellulose) CMC and gelatin. The prepared membrane was 
characterized using different techniques such as XRD, FT-IR, SEM, TGA and OM. The Rh B adsorption property of membrane was studied by varying parameters such as $\mathrm{pH}$, temperature, time, adsorbent amount and initial dye concentration. The kinetic and adsorption isotherm were used to determine the mechanism of dye adsorption. Finally, the recyclability tests were also studied.

\section{Experimental section}

\subsection{Materials}

Polyvinyl alcohol (PVA, $\left(\mathrm{C}_{2} \mathrm{H}_{4} \mathrm{O}\right.$, hydrolysis degree: 99\%) was obtained from Ajax Finechem Pvt. Ltd. (Thailand). Rhodamine $\mathrm{B}\left(\left(\mathrm{C}_{28} \mathrm{H}_{31} \mathrm{ClN}_{2} \mathrm{O}_{3}\right), \mathrm{Rh} B\right)$ and gelatine was purchased from Merck (Thailand). The cross-linking agent glutaraldehyde $\left(\mathrm{C}_{5} \mathrm{H}_{8} \mathrm{O}_{2} ; \mathrm{GA}\right)$ was purchased from Loba Chemie Products Limited. (Thailand). Carboxy methyl cellulose (CMC, $\left.\left(\mathrm{C}_{6} \mathrm{H}_{7} \mathrm{O}_{2}(\mathrm{OH})_{\mathrm{x}}\left(\mathrm{OCH}_{2} \mathrm{COONa}\right)_{\mathrm{y}}\right)_{\mathrm{n}}\right)$ and chitosan $\left(\mathrm{C}_{18} \mathrm{H}_{35} \mathrm{~N}_{3} \mathrm{O}_{13}\right)$ was provided by Chemipan (Thailand). Tetra propyl ammonium hydroxide $\left(\left(\mathrm{CH}_{3} \mathrm{CH}_{2} \mathrm{CH}_{2}\right)_{4} \mathrm{NOH}\right.$, TPAOH), tetraethyl orthosilicate $\left(\mathrm{C}_{8} \mathrm{H}_{20} \mathrm{O}_{4} \mathrm{Si}\right.$, TEOS $)$ and aluminum isopropoxide $\left(\mathrm{C}_{9} \mathrm{H}_{21} \mathrm{AlO}_{3}\right.$, AIP $)$ were procured from Sigma Aldrich Co. Ltd (India). All the chemicals were analytical grade and were used without further modification. The polymer solution and dye solution were prepared in distilled water.

\subsection{Preparation of ZSM-5 zeolite}

The synthesis procedure for hierarchical zeolite is as follows; initially $0.13 \mathrm{~g}$ of aluminium source (AIP) and structure directing agents (tetra propyl ammonium hydroxide) were mixed in distilled water under constant stirring at room temperature for $3 \mathrm{~h}$. To the properly mixed solution, silica source i.e., tetraethyl orthosilicate was added and the mixture was further stirred to form homogenized solution. This was followed by the addition of $2 \mathrm{~g}$ of chitosan (meso template). The resultant mixture was sonicated for $1 \mathrm{~h}$ in water bath to get a uniform dispersion. The mixture was then transferred into an autoclave and aged at $100^{\circ} \mathrm{C}$ for $6 \mathrm{~h}$ for further crystallisation. The product was collected by filtration, washed with distilled water, dried in oven, and then calcined at $550^{\circ} \mathrm{C}$ for $5 \mathrm{~h}$ in a muffle furnace to remove the meso/micro template.

\subsection{Membrane fabrication}

To the freshly prepared PVA solution, $1 \mathrm{wt} \% \mathrm{CMC}$ and $1.5 \mathrm{wt} \%$ gelatine was added. The solution was continuously stirred for $5 \mathrm{~h}$ to get uniform dispersion. Into the above solution, different weight percentage of zeolite which was previously sonicated in water bath was added 
and the solution was stirred for whole day. The cross-linking of the polymers was achieved by addition of $\mathrm{GA}$ and $3 \% \mathrm{HCl}$. Finally, the solution was poured into clean petri dish to form uniform thickness film. The membrane was dried at room temperature for 5 days and peeled off from the petri dish. For comparison studies, the plain membrane was prepared in similar manner without the addition of zeolite. The membrane loaded with $0,1,3$ and $5 \%$. Zeolite was denoted as PCGZ-0, PCGZ -1, PCGZ -2 and PCGZ -3 respectively. The membrane thickness was measured by screw gauge at different positions and the thickness was found to be $28 \pm 2$ $\mu \mathrm{m}$.

Table 1: The composition of the casting solution

\begin{tabular}{lcccc}
\hline Sample code & PVA & CMC & GEL & ZSM-5 zeolite \\
\hline PCGZ-0 & 9 & 1 & 1.5 & 0 \\
PCGZ-1 & 9 & 1 & 1.5 & 1 \\
PCGZ-2 & 9 & 1 & 1.5 & 3 \\
PCGZ-3 & 9 & 1 & 1.5 & 5 \\
\hline
\end{tabular}

\subsection{Characterisation}

The surface morphology of the membrane was performed using scanning electron microscope (FEI Quanta 450) with an accelerating voltage of $5 \mathrm{kV}$ and optical microscope (Olympus BX43 series) instrument. FT-IR spectroscopy was used to analysis the chemical composition of the membrane (Jasco 4700). The spectral was scanned in the range of $450-4000 \mathrm{~cm}^{-1}$ with a resolution of $4 \mathrm{~cm}^{-1}$. The tensile strength and elongation at break were calculated by UTM (Universal testing machine, QC-506M1-204) with $10 \mathrm{kN}$ load capacity and a crosshead speed of $10 \mathrm{~mm} / \mathrm{min}$. The hydrophilic/hydrophobic nature of the membranes was accessed using contact angle analysis (Drop Meter SCA data physics). Here, a small water droplet was released using inverted needle and droplet was directly placed on the membrane. The droplet was captured using microscope which was coupled with camera. The measurement was done in triplicate and average value was presented. Swelling experiment was carried out to understand the durability of membrane in water. Initially, membrane was weighed and subsequently immersed in $50 \mathrm{~mL}$ of distilled water for $48 \mathrm{~h}$ at room temperature. At different intervals, the swollen sample is removed from water, wiped and weight is noted. The process was continued until a constant weight is observed.

The percentage of swelling calculated by

$$
\text { Swelling ratio }=\frac{\mathrm{Ws}-\mathrm{Wd}}{\mathrm{Wd}} \times 100
$$


where $\mathrm{W}_{\mathrm{d}}$ and $\mathrm{W}_{\mathrm{s}}$ are the weight of dry and swollen membrane.

\subsection{Adsorption experiment}

The adsorption capacity of the PVA/CMC/GEL/ZSM-5 membrane was examined using a model dye; Rh B. For adsorption studies the membrane was agitated with $60 \mathrm{~mL}$ of $\mathrm{Rh} \mathrm{B}$ solution and after certain time period it was separated, filtered and the absorbance was measured using UV-visible spectrophotometer at a wavelength of $554 \mathrm{~nm}$. The percentage dye removal efficiency $(\mathrm{R} \%)$ and equilibrium adsorption capacity $\left(\mathrm{q}_{\mathrm{e}}\right)$ were evaluated using the equations.

$$
\begin{aligned}
\mathrm{q}_{\mathrm{e}} & =\frac{\left(\mathrm{C}_{0}-\mathrm{C}_{\mathrm{e}}\right) \mathrm{V}}{\mathrm{W}} \\
\mathrm{R}(\%) & =\frac{\mathrm{C}_{0}-\mathrm{C}_{\mathrm{e}}}{\mathrm{C}_{0}} \times 100
\end{aligned}
$$

Here $\mathrm{C}_{0}$ and $\mathrm{C}_{\mathrm{e}}$ represent the initial $(\mathrm{mg} / \mathrm{L})$ and equilibrium $(\mathrm{mg} / \mathrm{L})$ concentrations of $\mathrm{Rh} B$ respectively; V (L) is the volume of dye solution and $\mathrm{W}(\mathrm{g})$ is the weight of the adsorbent.

\subsection{Reusability}

The reusability test is an important factor for practical applications. The recyclability study was carried out by mixing $0.1 \mathrm{~g}$ of the membrane with $50 \mathrm{~mL}$ of dye solution to ensure the maximum contact between the membrane and dye molecules. Later the dye laden membrane was taken out, wash several times with distilled water and stirred with $1 \% \mathrm{HCl}$. The selection of solvent was based on the desorption efficiency of Rh B dye form the membrane. After the desorption process, the membrane was separated, washed, dried and reused for next cycle. The process is repeated for another six cycle to evaluate the reusability property of the membrane [30].

\section{Results and discussion}

\subsection{Characterization of PVA/CMC/GEL/ZSM-5 membrane}

Figure 1 illustrate the FT-IR spectra of plain PVA/CMC/GEL and zeolite loaded PVA/CMC/GEL membrane. The broad band observed at $3280 \mathrm{~cm}^{-1}$ is characteristics of -OH stretching of PVA, CMC and gelatine respectively. The peak located at $2920 \mathrm{~cm}^{-1}$ can be attributed to $\mathrm{C}-\mathrm{H}$ stretching of polymers. The two bands observed at 1660 and 
$1420 \mathrm{~cm}^{-1}$ corresponds to asymmetric and symmetric stretching of -COOH group of PVA and CMC respectively. The absorption peak at $1065 \mathrm{~cm}^{-1}$ is assigned to $\mathrm{Si}-\mathrm{O}$ stretching of zeolite. The main peak observed at $520 \mathrm{~cm}^{-1}$ corresponds to $\mathrm{Si}-\mathrm{O}-\mathrm{Si}$ and Al-O-Si respectively. The emergence of new peaks at 1106, 802 and $441 \mathrm{~cm}^{-1}$ for zeolite loaded membrane corresponds to $\mathrm{Si}-\mathrm{O}$ and Al-O bond stretching [38-41]. The surface morphology of membrane was observed through SEM technique. As can be seen in Figure 2, zeolite incorporation has a significant effect on the surface roughness of PVA/CMC/GEL membrane. It is also evident that membrane loaded with high percent of zeolite $(5 \mathrm{wt} \%)$ has greater particle distribution. However, at high zeolite dosage $(>5 \mathrm{wt} \%)$, the particles tend to agglomerate and thereby reduce its adsorption ability. Therefore, we choose $5 \mathrm{wt} \%$ zeolite as the optimum zeolite dosage. These observations were complementary to optical microscopic analysis and confirmed the successful incorporation of zeolite in the membrane (Figure 3) [38]. X-ray diffraction pattern of plain $\mathrm{PVA} / \mathrm{CMC} / \mathrm{GEL}$ and zeolite loaded PVA/CMC/GEL is displayed in Figure 4. The semi crystalline nature of polymers was observed at $2 \theta=19.9^{\circ}$. The diffraction peak at $2 \theta=24.3^{\circ}$ and $25.6^{\circ}$ for zeolite loaded membrane is attributed to the MFI structure of zeolite. It can also observe that with increase in zeolite dosage, the intensity of characteristic peak of zeolite at $2 \theta=24.3^{\circ}$ increases. Meanwhile, a diminishing intensity was noted for peaks at $2 \theta=19.9^{\circ}[34$, $42,43]$. The wettability of the membrane was monitored by contact angle analysis and the results are presented in Figure 5. Owing to its hydrophobic nature, zeolite will decrease the hydrophilic nature of PVA/CMC membrane. Therefore, on increasing the zeolite percentage, the value of water contact angle also increases and a maximum contact angle was observed $\left(85^{\circ}\right)$ for $5 \mathrm{wt} \%$ zeolite loaded membrane. Consequently, the water droplet on the membrane become spherical with zeolite dosage. Swelling is an important parameter for adsorption application. The swelling capacity of membrane depends on cross-linking density, $\mathrm{pH}$ and temperature. PVA, gelatine and CMC are hydrophilic polymers and therefore it has greater affinity for water. Hence, we observed high degree of swelling (97\%) for PVA/CMC/GEL/ZSM-5 membrane. However, the addition of zeolite decreases the swelling. This is ascribed to the hydrophobic nature of zeolite. The membrane with desirable mechanical properties is preferred for water treatment application. This prompted us to examine the mechanical property of PVA/CMC/GEL/ZSM-5 membrane. The effect of ZSM-5 zeolite on the mechanical properties of PVA/CMC/GEL membrane is shown in Table 1. It can be seen that tensile strength of the membrane increases with increase in zeolite loading. This implies 
that zeolite particle acts as filler and thereby strengthen the polymer matrix. However, a reduction in elongation at break value was noted with zeolite content $[44,45]$.

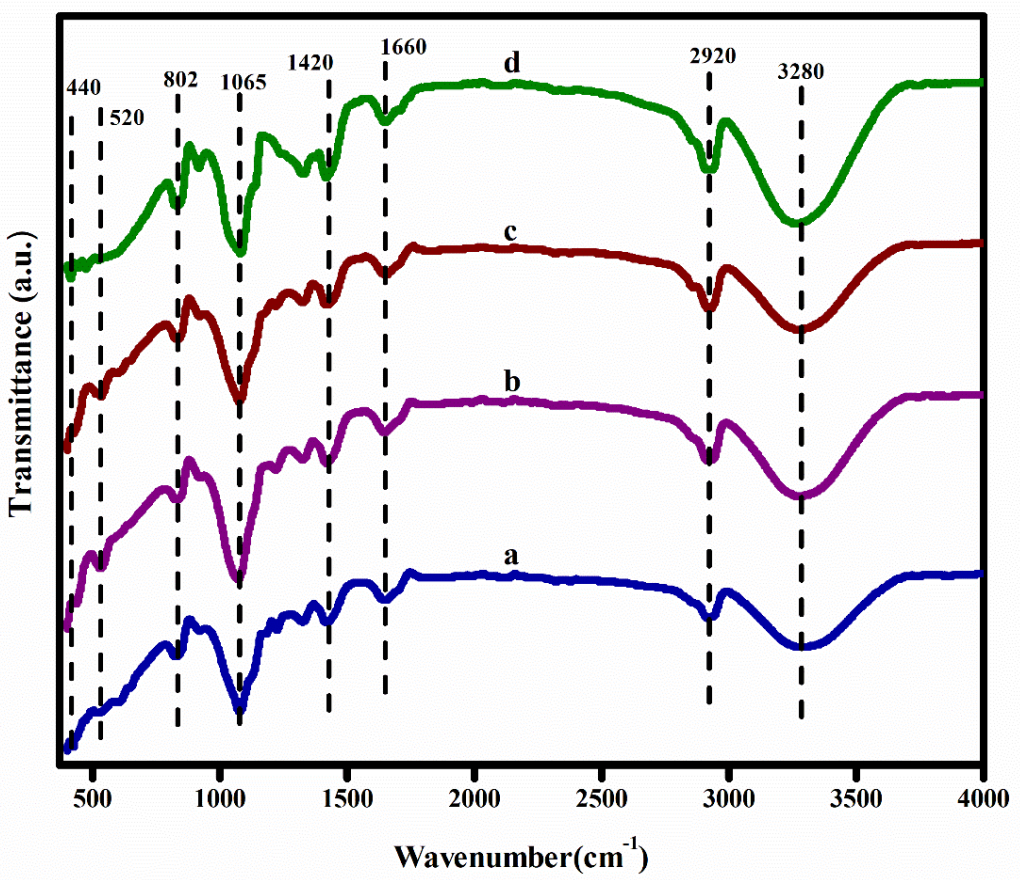

Figure 1. FT-IR spectra of PVA/CMC/GEL/ZSM-5 membranes: (a) PCGZ-0; (b) PCGZ -1; (c) PCGZ -2; (d) PCGZ -3
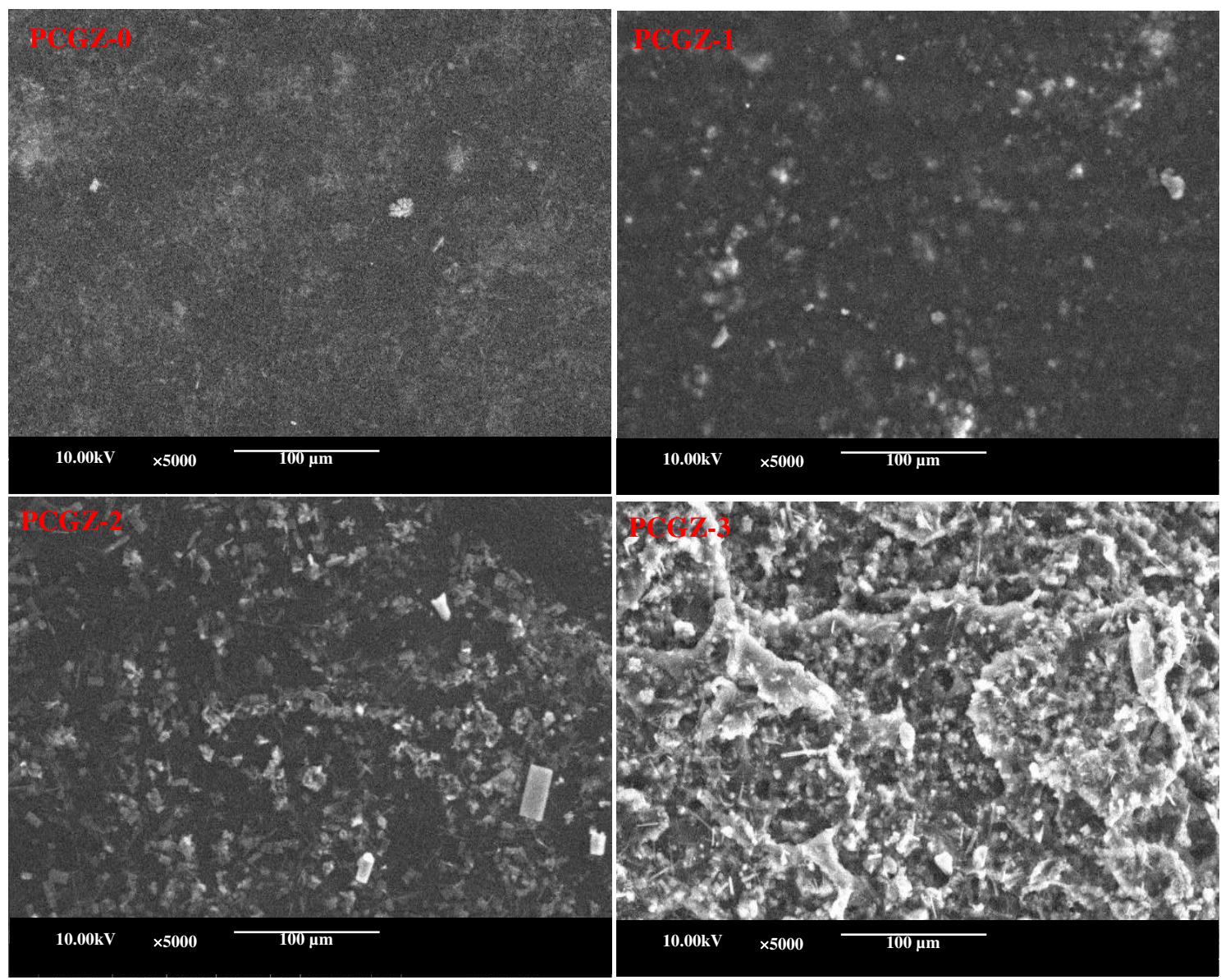

Figure 2. SEM images of different zeolite loaded PVA/CMC/GEL membranes 

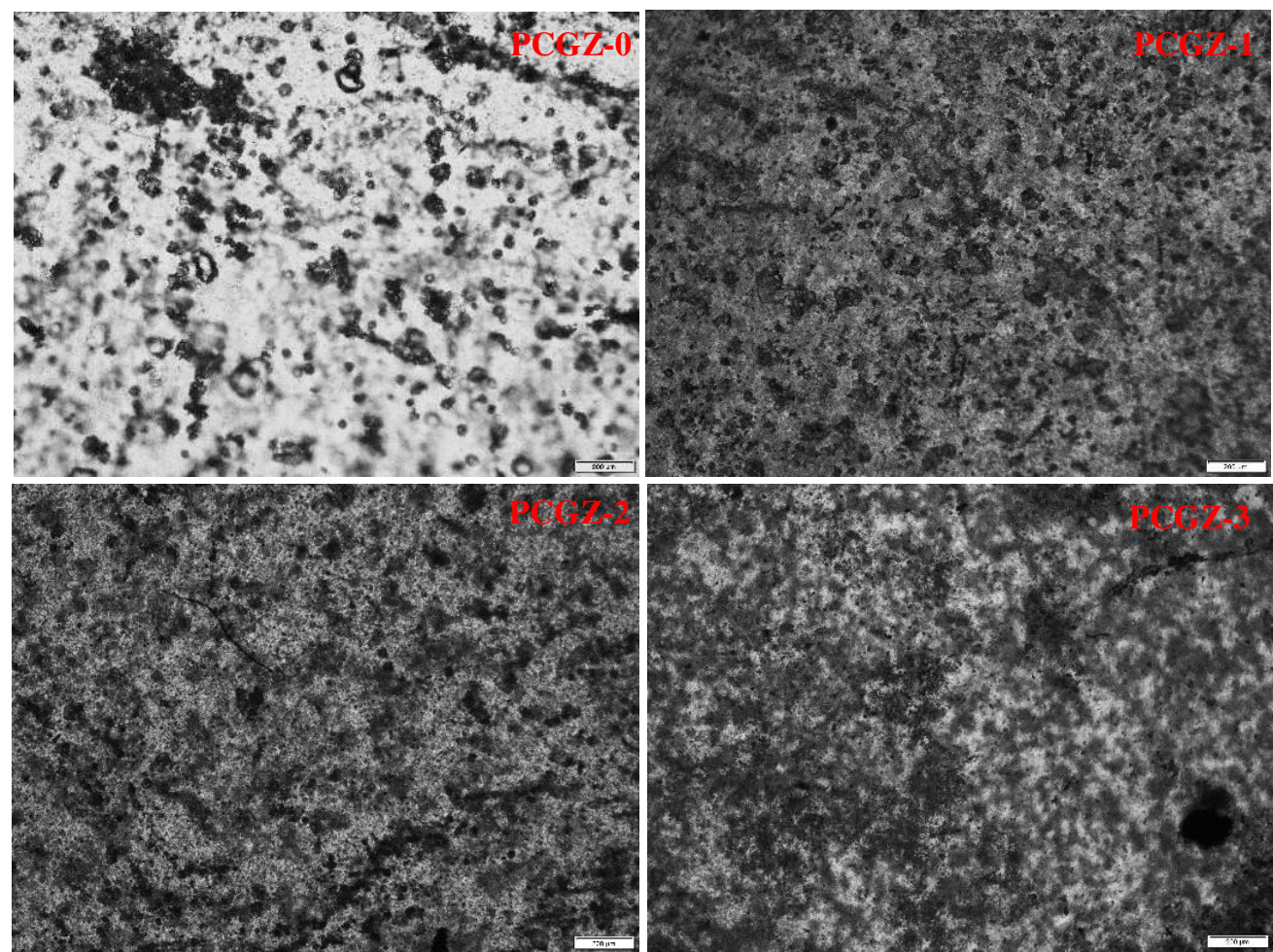

Figure 3. Optical microscopic images of different zeolite loaded PVA/CMC/GEL membranes

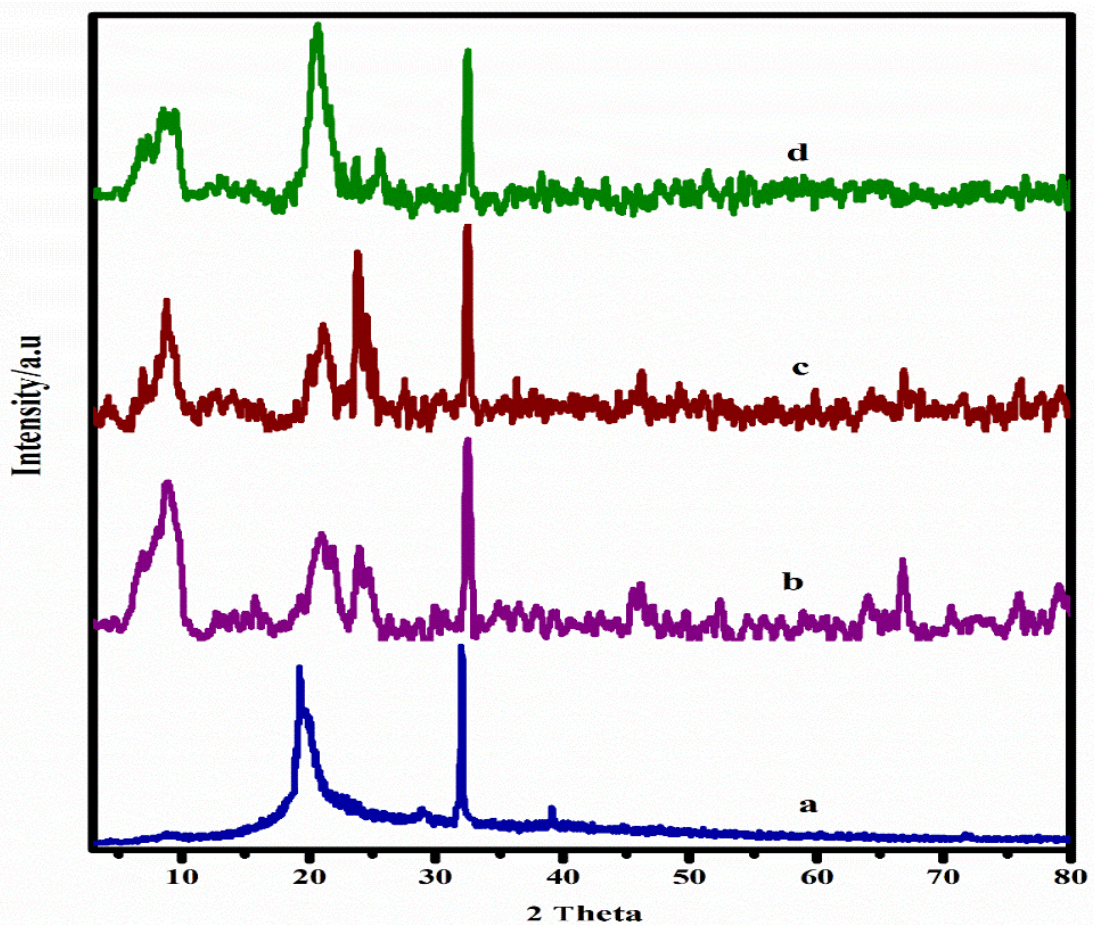

Figure 4. XRD pattern of different zeolite loaded PVA/CMC/GEL membranes: (a) PCGZ-0; (b) PCGZ -1; (c) PCGZ -2; (d) PCGZ -3 


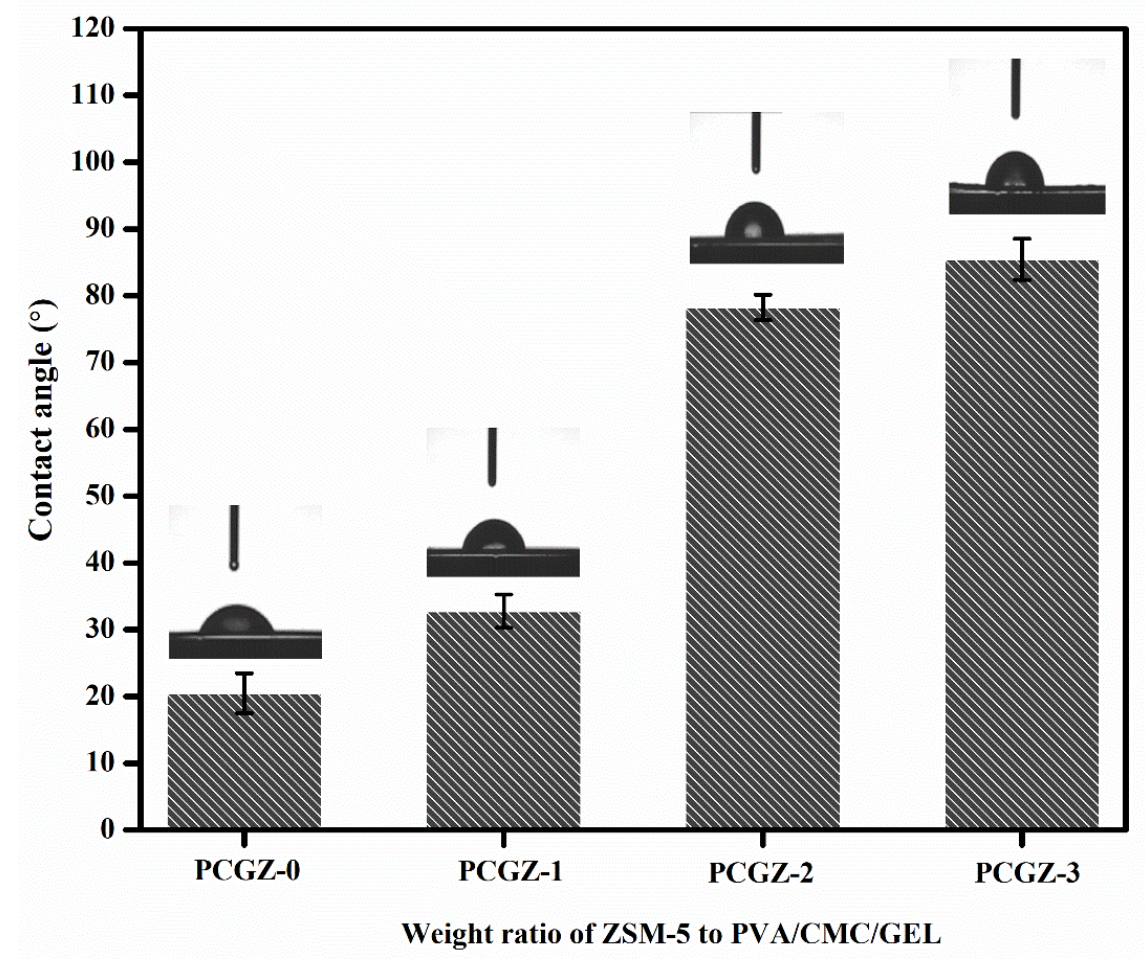

Figure 5. Water contact angle of different zeolite loaded PVA/CMC/GEL membranes

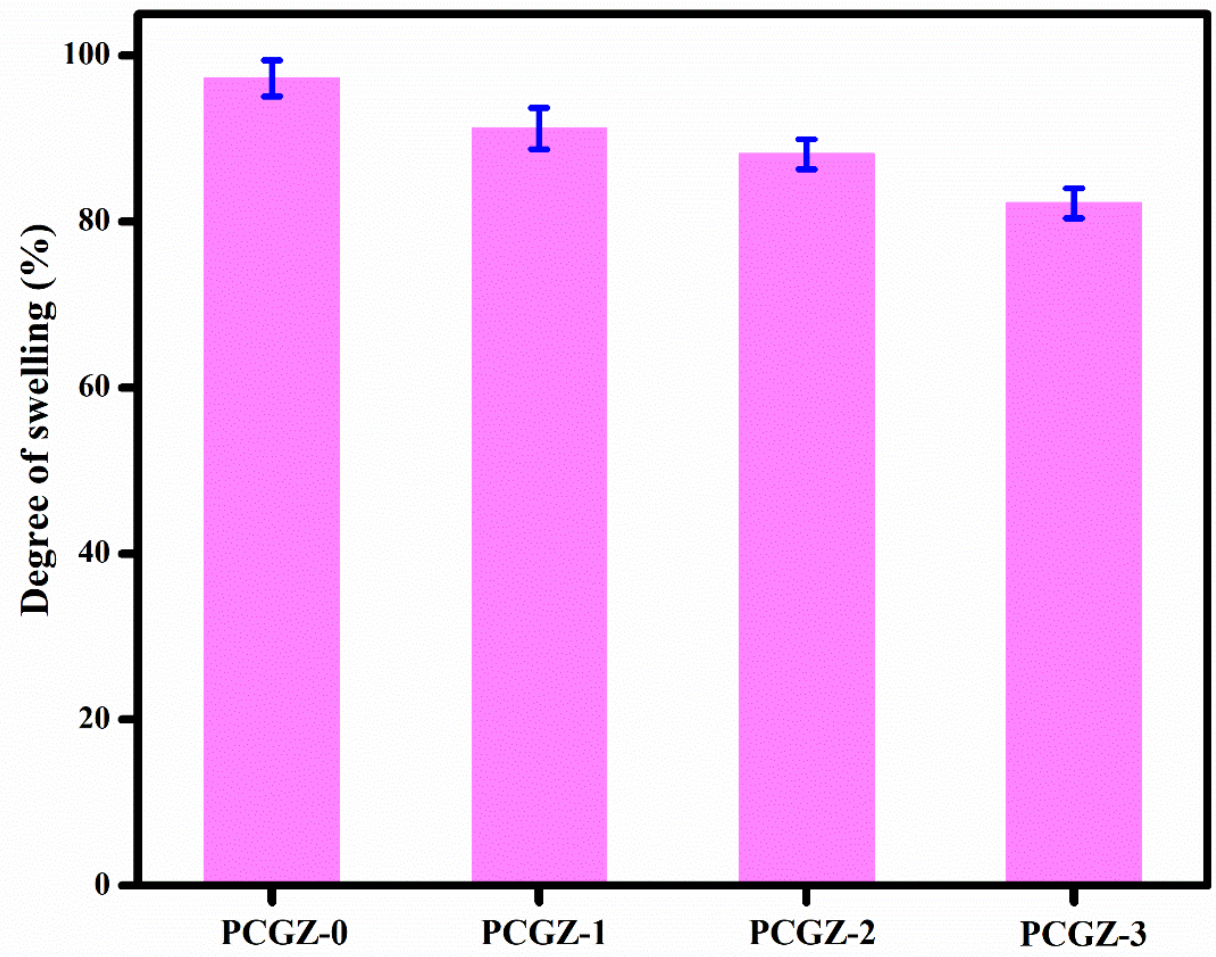

Figure 6. Degree of swelling of different zeolite loaded PVA/CMC/GEL membranes 
Table 1. Mechanical properties of PVA/CMC/GEL/ZSM-5 membrane

\begin{tabular}{ccc}
\hline Samples & Tensile Strength $\left(\mathbf{N} / \mathbf{m m}^{\mathbf{2}}\right)$ & Elongation at break (\%) \\
\hline PCGZ-0 & 10.69 & 62.17 \\
PCGZ-1 & 33.34 & 35.96 \\
PCGZ-2 & 52.73 & 34.50 \\
PCGZ-3 & 63.15 & 28.65 \\
\hline
\end{tabular}

\subsection{Adsorption experiments}

The effect of zeolite dosage on the Rh B dye removal was investigated and the result is shown in Figure 7(a). It can be noted that on increasing the amount of zeolite from 1 to $5 \%$, the adsorption capacity of the membrane increases and a maximum adsorption efficiency (97\%) was noted for $5 \mathrm{wt} \%$ loaded membrane. The rapid enhancement observed for zeolite loaded membrane is due to the large surface area and availability of more active sites present on the adsorbent $[46,47]$. Scheme 1 show the schematic representation of different percentage of zeolite on PVA/CMC/GEL membrane will interact with $\mathrm{Rh} B$ dye molecule. However, no significant improvement in the removal efficiency was noted for membrane loaded with zeolite percentage greater than $5 \mathrm{wt} \%$. This could be due to the agglomeration of zeolite particle on the surface of membrane. The initial dye concentration plays a major role in controlling the removal percentage and adsorption capacity of membrane. The effect of initial dye concentration on the dye removal ability of PVA/CMC/GEL/ZSM-5 zeolite membrane is show in Figure 7(b). On increasing the initial dye concentration, the effective collision between the membrane and Rh B molecule increases. This leads to enhancement of adsorption capacity. Meanwhile, a reduction in removal efficiency was noted with increase in initial concentration. Similar trend was reported by Liu, Han and Vimonses [48-50] and it was attributed to the reduction of adsorption sites on the membrane. $\mathrm{pH}$ will affect the charge and surface binding site of an adsorbent. Therefore, we have varied the $\mathrm{pH}$ of solution from 2 to 10 and studied its effect on $\mathrm{Rh} \mathrm{B}$ removal (Figure 7(c)). At low $\mathrm{pH}$, the solution contains large number of $\mathrm{H}^{+}$ions and thereby protonate the membrane. Consequently, the membrane will repel positive charge $\mathrm{Rh} \mathrm{B}$ dye molecule and the adsorption capacity decreases. Furthermore, the excess $\mathrm{H}^{+}$on the aqueous solution will compete with the cationic dye ( $\mathrm{Rh} \mathrm{B})$ for the same adsorption site. This is also responsible for the low adsorption capacity at acidic $\mathrm{pH}$. However, at basic $\mathrm{pH}$, the membrane has greater tendency to attract positively charged cationic dye through electrostatic 
attraction. The maximum adsorption capacity of $\mathrm{Rh} \mathrm{B}$ on the membrane at basic $\mathrm{pH}$ was 10 $[51,52]$. Figure 7(d) show the effect of contact time on Rh B dye removal efficiency of PVA/CMC/GEL/ZSM-5 zeolite membrane. In the initial contact time, due to the availably of the large number of free adsorption sites, the Rh B dye adsorption occurs very rapidly. This is reflected in the adsorption capacity value $\left(\mathrm{q}_{\mathrm{e}}=4.85\right)$. After $1.30 \mathrm{~h}$, the adsorption capacity increases only slowly with contact time and finally after $3 \mathrm{~h}$ it reaches equilibrium. This is due to the saturation of binding site [53-55]. Temperature plays an important role on the dye adsorption process. We have monitored the dye adsorption capacity of the membrane at different temperature range i.e., 30 to $60{ }^{\circ} \mathrm{C}$ (Figure 7(e)). The result revealed that the on increasing the temperature from 30 to $60^{\circ} \mathrm{C}$, the adsorption capacity decreases. This indicate that adsorption of $\mathrm{Rh} \mathrm{B}$ onto the membrane is exothermic in nature [51]. 


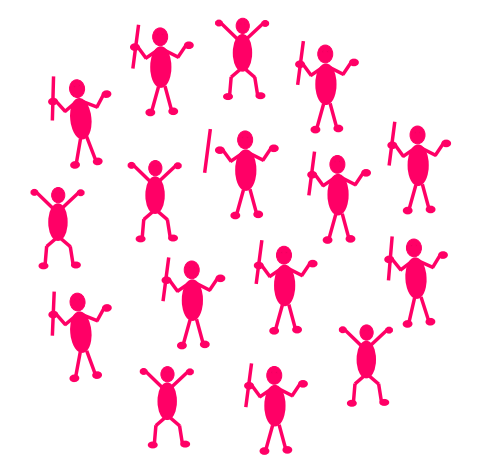

Rhodamine B

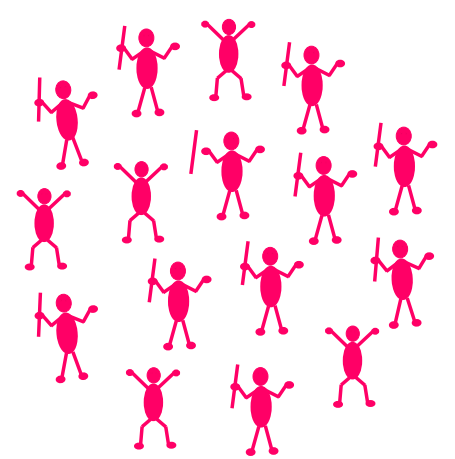

Rhodamine B
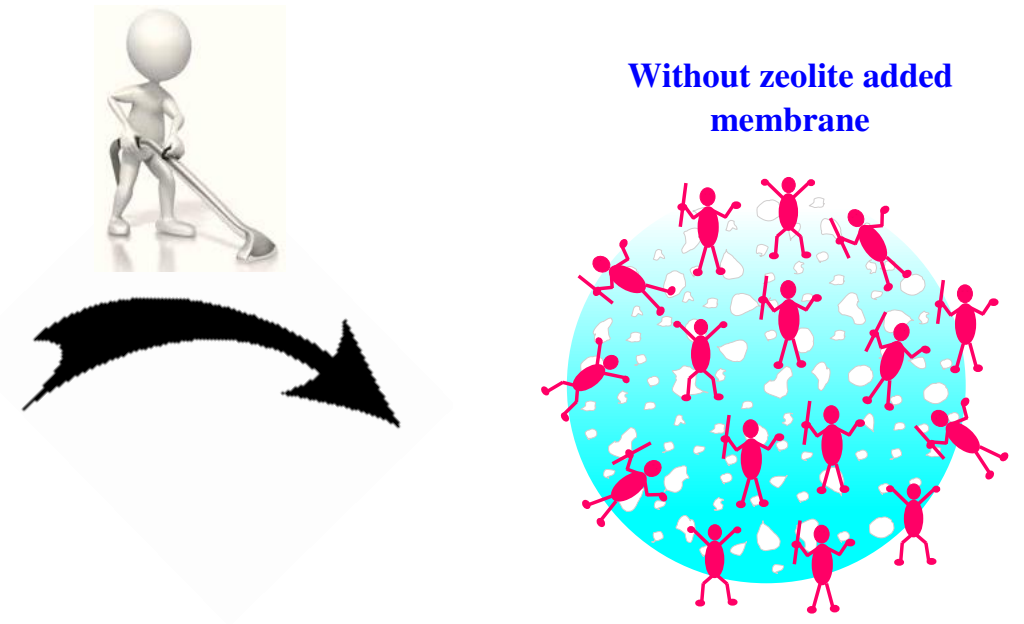

Less Rh B adsorbed on the surface
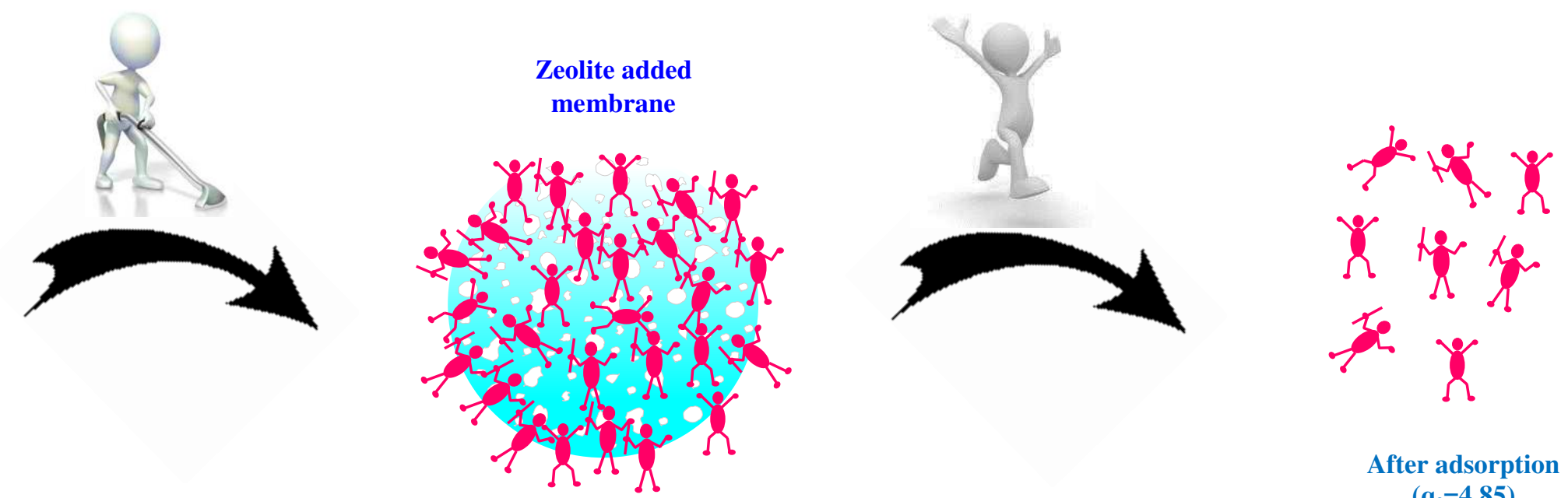

After adsorption $\left(\mathrm{q}_{\mathrm{e}}=\mathbf{4 . 8 5}\right)$

Scheme 1: Rhodamine B dye molecules adsorbed on the membrane 

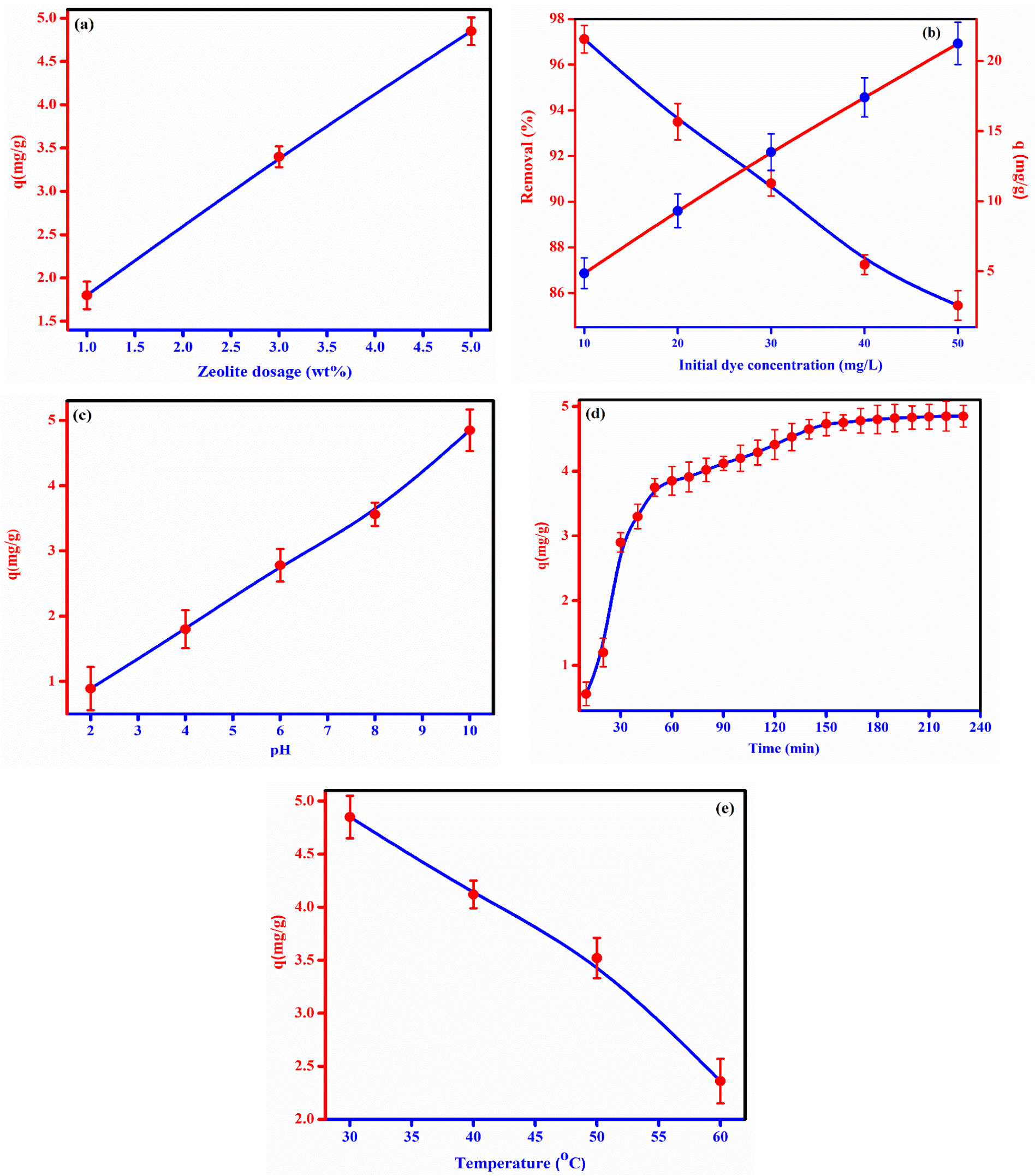

Figure 7. The effect of different parameters such as a) zeolite dosage; b) initial dye concentration; c) $\mathrm{pH}$ d) contact time; and e) temperature on the removal of $\mathrm{Rh} \mathrm{B}$ dye using PVA/CMC/GEL/ZSM-5 membrane (Experimental condition: adsorbent dosage $=5 \mathrm{wt} \%$, initial dye concentration $=10 \mathrm{ppm}$, contact time $=180 \mathrm{~min}, \mathrm{pH}=10$ and temperature $=30^{\circ} \mathrm{C}$ ) 


\subsection{Adsorption isotherm}

The adsorption isotherm is employed to explain the distribution of adsorbate between the solid and liquid. In this study, the relationship between the adsorbate and the adsorbent was understand using two well-known isotherm models namely Langmuir and Freundlich isotherms

\section{Langmuir isotherm}

Langmuir isotherm model indicate monolayer adsorption on the homogeneous surface. The linear form of Langmuir isotherm model is as follows [52]

$$
\frac{\mathrm{C}_{\mathrm{e}}}{\mathrm{q}_{\mathrm{e}}}=\left(\frac{\mathrm{C}_{\mathrm{e}}}{\mathrm{q}_{\mathrm{m}}}\right)+\left(\frac{1}{\mathrm{~K}_{\mathrm{L}} * \mathrm{q}_{\mathrm{m}}}\right)
$$

where $\mathrm{q}_{\mathrm{e}}$ and $\mathrm{C}_{\mathrm{e}}$ corresponds to the equilibrium adsorption capacity $(\mathrm{mg} / \mathrm{g})$ and equilibrium concentration of adsorbate $(\mathrm{mg} / \mathrm{L})$ respectively. $\mathrm{K}_{\mathrm{L}}$ is Langmuir constant and is related to the affinity of binding site. $\mathrm{q}_{\mathrm{m}}$ is monolayer adsorption capacity $(\mathrm{mg} / \mathrm{g})$. The value of $\mathrm{q}_{\mathrm{e}}$ and $\mathrm{K}_{\mathrm{L}}$ were obtained from the slope and intercept of the linear plot $\mathrm{C}_{\mathrm{e}} / \mathrm{q}_{\mathrm{e}}$ against $\mathrm{C}_{\mathrm{e}}$ (Figure 8). The nature of adsorption is related to dimensionless constant $\mathrm{R}_{\mathrm{L}}$ (separation factor) which is mathematically represented as follows;

$$
\mathrm{R}_{\mathrm{L}}=\frac{1}{1+\mathrm{K}_{\mathrm{L}} \mathrm{C}_{0}}
$$

The value of $R_{L}$ between 0-1 is indicates a favorable adsorption. If the value of $R_{L}$ is not in the aforementioned range it is considered as unfavorable $\left(R_{L}>1\right)$, linear $\left(R_{L}=1\right)$ and irreversible $\left(\mathrm{R}_{\mathrm{L}}=0\right)$.

\section{Freundlich isotherm}

Freundlich isotherm model assumes a multilayer adsorption and thus suggest a heterogenous adsorbent surface [56]. The linearized form of the equation is

$$
\ln \left(\mathrm{q}_{\mathrm{e}}\right)=\operatorname{In} \mathrm{K}_{\mathrm{F}}+\frac{1}{\mathrm{n}} * \operatorname{In}\left(\mathrm{C}_{\mathrm{e}}\right)
$$

Here $\mathrm{C}_{\mathrm{e}}$ is the equilibrium concentration of $\mathrm{Rh} B$ solution $(\mathrm{mmol} / \mathrm{L}), \mathrm{q}_{\mathrm{m}}$ is the maximum absorption capacity (mg/g), $\mathrm{q}_{\mathrm{e}}$ is the amount of $\mathrm{Rh} \mathrm{B}$ dye adsorbed at equilibrium and $\mathrm{K}_{\mathrm{L}}$ is a Langmuir isotherm constant. The value of $\mathrm{q}_{\max }$ and $\mathrm{K}_{\mathrm{L}}$ values are calculated from the intercept and slope of the graph plotted against $\ln \mathrm{q}_{\mathrm{e}}$ verses $\ln \mathrm{C}_{\mathrm{e}}$ (Figure 8). 
The value of $1 / \mathrm{n}$ is used to predict the favourability of the adsorption. The value between 0 and 1 implies a favourable adsorption. If the value is greater than zero then it is considered as irreversible whereas $1 / \mathrm{n}=0$ represent an unfavourable adsorption. The values of isotherm parameters are shown in Table 2. It can be seen clearly from table 2 that adsorption data fitted well in the Freundlich model. Also, the correlation coefficient $\left(\mathrm{R}^{2}\right)$ for Freundlich model $\left(\mathrm{R}^{2}: 0.999\right)$ fitted better than that of Langmuir model $\left(\mathrm{R}^{2}: 0.97\right)$. The result thus implies that the adsorption of $\mathrm{Rh} \mathrm{B}$ dye onto PVA/CMC/GEL/ZSM-5 zeolite membrane is heterogeneous in nature $[50,57]$.
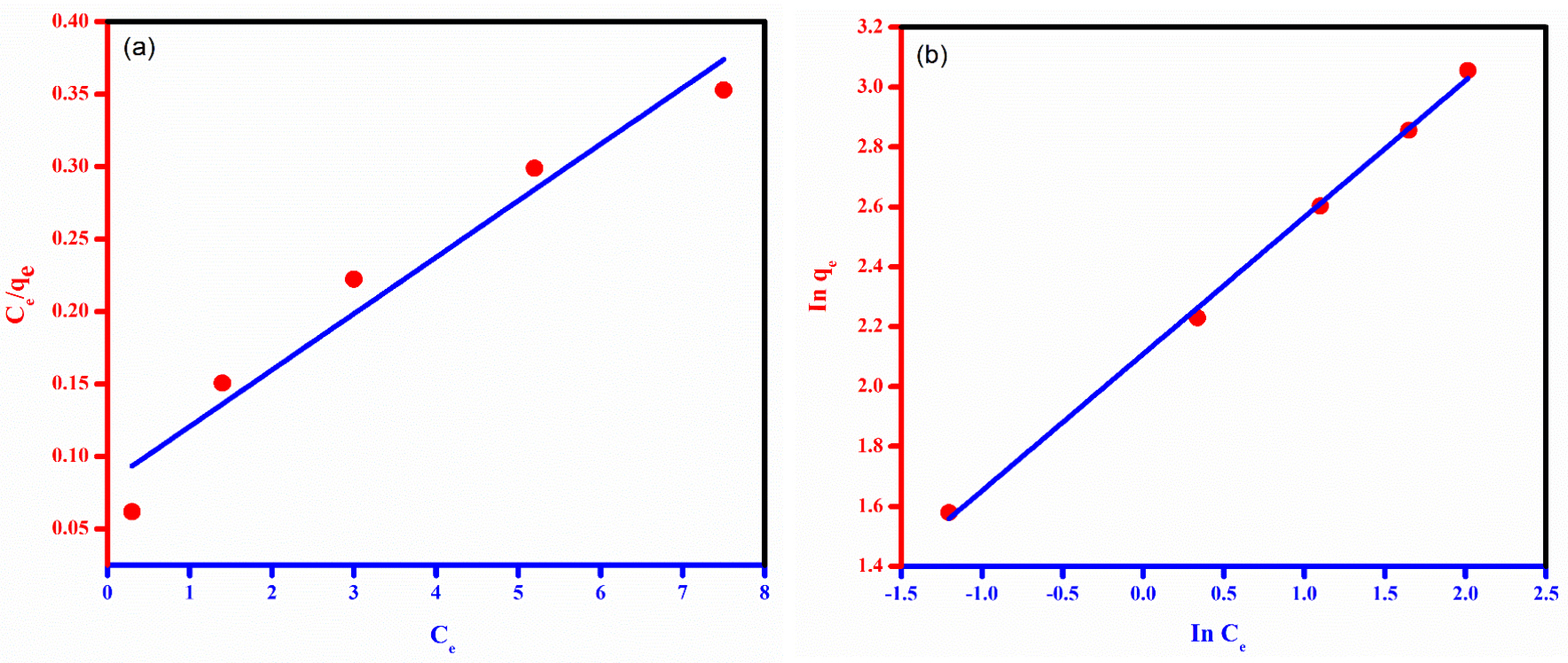

Figure 8. Isotherm model plots for the adsorption of $\mathrm{Rh} \mathrm{B}$ dye removal using PVA/CMC/GEL/ZSM-5 membrane (Experimental condition: adsorbent dosage $=5 \mathrm{wt} \%$, initial dye concentration $=10 \mathrm{ppm}$, contact time $=180 \mathrm{~min}, \mathrm{pH}=10$ and temperature $=30^{\circ} \mathrm{C}$ )

Table 2. Parameter values of adsorption isotherm

\begin{tabular}{ccccccc}
\hline Experimental & \multicolumn{3}{c}{ Langmuir isotherm } & \multicolumn{3}{c}{ Freundlich isotherm } \\
\hline $\mathrm{q}_{\mathrm{e}}, \exp \left(\mathrm{mg} \mathrm{g}^{-1}\right)$ & $\mathrm{R}^{2}$ & $\mathrm{q}_{\max }\left(\mathrm{mg} \mathrm{g}^{-1}\right)$ & $\mathrm{K}_{\mathrm{L}}$ & $\mathrm{R}^{2}$ & $\mathrm{~K}_{\mathrm{F}}\left(\mathrm{mg} \mathrm{g}^{-1}\right)$ & $\mathrm{n}$ \\
\hline 4.85 & 0.977 & 25.57 & 0.476 & 0.999 & 8.2 & 2.2 \\
& & & & & & \\
\hline
\end{tabular}

\subsection{Adsorption kinetics}

In order to predict the adsorption mechanism of Rh B onto PVA/CMC/GEL/ZSM-5 zeolite membrane, both pseudo-first-order (PFO) and pseudo-second-order (PSO) models were used. The linearized form of PFO and PSO models are expressed by equation 6 and 7 . 


$$
\begin{gathered}
\log \left(\mathrm{q}_{\mathrm{e}}-\mathrm{q}_{\mathrm{t}}\right)=\log \mathrm{q}_{\mathrm{e}}-\frac{\mathrm{K}_{1} \mathrm{t}}{2.303} \\
\frac{\mathrm{t}}{\mathrm{q}_{\mathrm{e}}}=\frac{1}{\mathrm{~K}_{2} \mathrm{q}_{\mathrm{e}}^{2}}+\frac{\mathrm{t}}{\mathrm{q}_{\mathrm{e}}}
\end{gathered}
$$

where $\mathrm{q}_{\mathrm{t}}$ represents the amount of $\mathrm{Rh} \mathrm{B}$ adsorbed on PVA/CMC/GEL/ZSM-5 zeolite membrane at time ' $\mathrm{t}$ ' and $\mathrm{q}_{\mathrm{e}}$ is the amount of $\mathrm{Rh} \mathrm{B}$ adsorbed on PVA/CMC/GEL/ZSM-5 zeolite membrane at equilibrium $(\mathrm{mg} / \mathrm{g})$ respectively. $\mathrm{K}_{1}$ and $\mathrm{K}_{2}$ are pseudo-first-order and pseudosecond-order rate constant with unit $\mathrm{min}^{-1}$ and $\mathrm{g} / \mathrm{mg} \min$ respectively. The equilibrium adsorption capacity $\left(\mathrm{q}_{\mathrm{e}}\right)$ and kinetic parameter such as rate constant $\left(\mathrm{K}_{1}\right.$ and $\left.\mathrm{K}_{2}\right)$ were determined from the slope and intercept of the linear plot of PFO $\left(\log \left(\mathrm{q}_{\mathrm{e}}-\mathrm{q}_{\mathrm{t}}\right) \mathrm{vs} \mathrm{t}\right)$ and PSO (t/qt vs $t)$. The value of kinetic parameters $\left(\mathrm{K}_{1}, \mathrm{~K}_{2}, \mathrm{q}_{\mathrm{e}}\right.$ and $\left.\mathrm{R}^{2}\right)$ for dye adsorption is listed in Table 3. From the table 3, it is clear that the adsorption data fitted well with PSO with high correlation value $\left(\mathrm{R}^{2}=0.97\right)$. It can be also noted that the experimental and calculated $\mathrm{q}_{\mathrm{e}}$ values was in good agreement with pseudo-second-order. Therefore, PSO model is most suitable to explain the kinetic of Rh B adsorption on PVA/CMC/GEL/ZSM-5 zeolite membrane than PFO model which has low correlation coefficient $\left(\mathrm{R}^{2}\right)[48,58,59]$. 

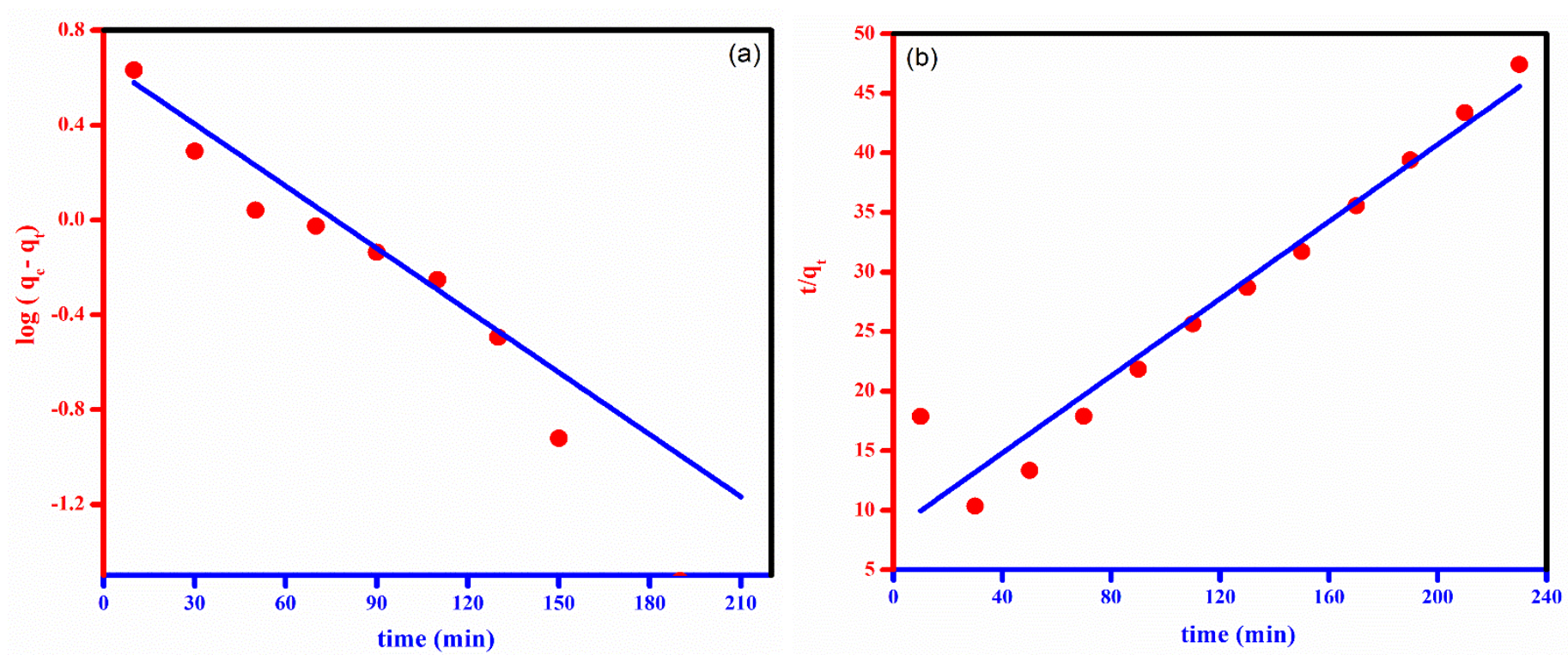

Figure 9. $\mathrm{PFO}$ and PSO kinetic models related to the adsorption of $\mathrm{Rh} \mathrm{B}$ on PVA/CMC/GEL/ZSM-5 zeolite membrane (Experimental condition: adsorbent dosage $=5$ $\mathrm{wt} \%$, initial dye concentration $=10 \mathrm{ppm}$, contact time $=180 \mathrm{~min}, \mathrm{pH}=10$ and temperature $=$ $\left.30^{\circ} \mathrm{C}\right)$

Table 3. Summary of parameter values of adsorption kinetics for $\mathrm{Rh} B$ onto PVA/CMC/GEL/ZSM-5 zeolite membrane

\begin{tabular}{ccccccc}
\hline Experimental & \multicolumn{3}{c}{ PFO } & & PSO & \\
\hline $\mathrm{q}_{\mathrm{e}}, \exp \left(\mathrm{mg} \mathrm{g}^{-1}\right)$ & $\mathrm{K}_{1}\left(\mathrm{~min}^{-1}\right)$ & $\mathrm{q}_{\mathrm{e}}\left(\mathrm{mg} \mathrm{g}^{-1}\right)$ & $\mathrm{R}^{2}$ & $\mathrm{~K}_{2}\left(\mathrm{~g} \mathrm{mg}^{-1} \mathrm{~min}^{-1}\right)$ & $\mathrm{qe}_{\mathrm{e}}\left(\mathrm{mg} \mathrm{g}^{-1}\right)$ & $\mathrm{R}^{2}$ \\
\hline 4.85 & -0.020 & 4.64 & 0.63 & 0.0031 & 6.17 & 0.97 \\
\hline
\end{tabular}

\subsection{Reusability}

Reusability tests is very essential for practical applications. The recyclability of PVA/CMC/GEL/ZSM-5 zeolite membrane is shown in Figure 10. It can be seen that even after six successive cycles, the membrane possesses high removal efficiency. A slow decrease in the removal efficiency was noted on moving from first to sixth recycle. This is due incomplete removal of adsorbed dye from the membrane. 


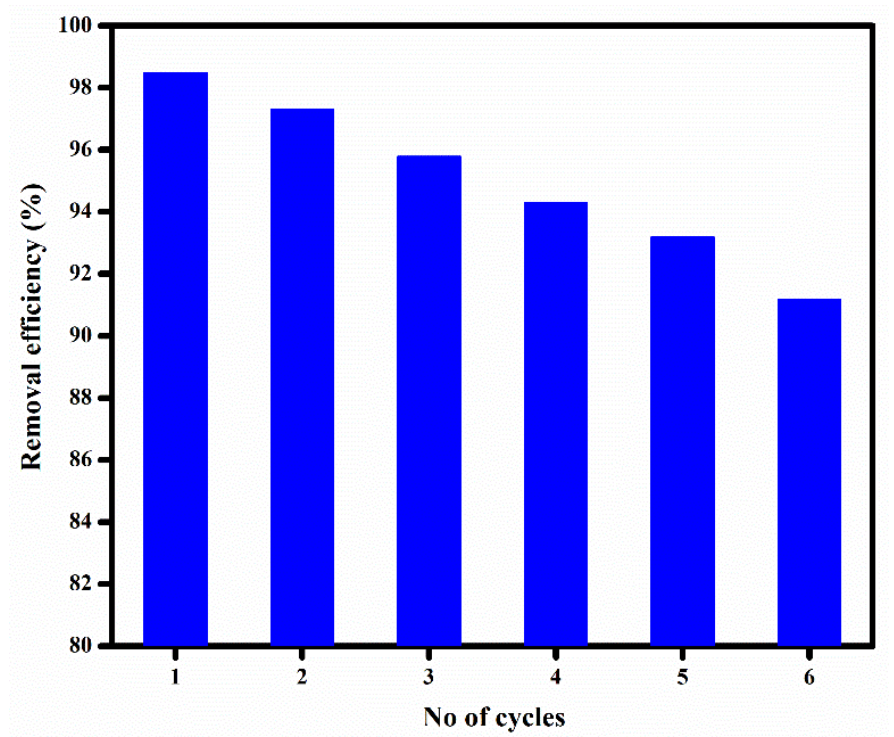

Figure 10. Reusability of Rh B dye after adsorption from PVA/CMC/GEL/ZSM-5 membrane

\section{Conclusion}

In this study, we developed ZSM-5 zeolite incorporated PVA/CMC/GEL membrane and applied it as an adsorbent for $\mathrm{Rh} \mathrm{B}$ removal from the aqueous solution. The membrane was characterized using different techniques such as XRD, FT-IR, SEM, optical microscopy, contact angle and UTM. We observed that the with the addition of zeolite, the physical properties (mechanical, crystallinity etc.) as well as the adsorption properties of the membrane gets improved. The batch adsorption studies shows that initial dye concentration, $\mathrm{pH}$, zeolite dosage and temperature play a major role in the $\mathrm{Rh} B$ dye removal using PVA/CMC/GEL/ZSM-5 zeolite membrane. The maximum adsorption was achieved at pH-10 with initial dye concentration-10 ppm. The adsorption data was well fitted with the Freundlich isotherm and pseudo-second-order model. Recyclability studies shows that membrane retains good adsorption capacity (91\%) even after six cycles. Our result thus suggests that PVA/CMC/GEL/ZSM-5 zeolite membrane is an efficient adsorbent for the dye removal from aqueous solution.

\section{Declarations}

\section{Ethics approval and consent to participate}

The article we have submitted to the journal for review is original, has been written by the stated authors and has not been published elsewhere. The images that we have submitted to the journal for review are original, and has not been published elsewhere. This manuscript has not been submitted to, nor is under review at, another journal or other publishing venue. The 
authors have no affiliation with any organization with a direct or indirect financial interest in the subject matter discussed in the manuscript.

\section{Competing interests}

The authors don't have any conflicts of interests.

\section{Consent for publication}

The authors confirm the consent for publication

\section{Availability of data and material}

All data generated or analysed during this study are included in this published article

\section{Funding}

(Grant No. KMUTNB-64-Post-03 to SR) and (Grant No. KMUTNB-63-03)

\section{Acknowledgements}

Authors gratefully thanks the Centre of Innovation in Design and Engineering for Manufacturing (CoI- DEM), KMUTNB, Thailand for characterization facilities to carry out this study. The study was financially supported by the King Mongkut's University of Technology North Bangkok (KMUTNB), Thailand through the Post-Doctoral Program (Grant No. KMUTNB-64-Post-03 and KMUTNB-63-Post-03 to SR)

\section{Compliance with ethical standards}

Conflict of interest: The authors have declared no conflict of interest

\section{Reference}

[1] P.H. Gleick, Water in Crisis: Paths to Sustainable Water Use, Ecological Applications 8(3) (1998) 571-579.

[2] S. Asadi, S. Eris, and S. Azizian, Alginate-Based Hydrogel Beads as a Biocompatible and Efficient Adsorbent for Dye Removal from Aqueous Solutions, ACS Omega 3(11) (2018) 15140-15148.

[3] R.R. Mohamed, M.H. Abu Elella, M.W. Sabaa, and G.R. Saad, Synthesis of an efficient adsorbent hydrogel based on biodegradable polymers for removing crystal violet dye from aqueous solution, Cellulose 25(11) (2018) 6513-6529.

[4] A. Talaiekhozani and S. Rezania, Application of photosynthetic bacteria for removal of heavy metals, macro-pollutants and dye from wastewater: A review, Journal of Water Process Engineering 19(2017) 312-321.

[5] S.K. Kahlon, G. Sharma, J.M. Julka, A. Kumar, S. Sharma, and F.J. Stadler, Impact of heavy metals and nanoparticles on aquatic biota, Environmental Chemistry Letters 16(3) (2018) 919-946.

[6] O. Duman, T.G. Polat, C.Ö. Diker, and S. Tunç, Agar/k-carrageenan composite hydrogel adsorbent for the removal of Methylene Blue from water, International Journal of Biological Macromolecules 160(2020) 823-835.

[7] H. Ali, Biodegradation of Synthetic Dyes-A Review, Water, Air, \& Soil Pollution 213(1-4) (2010) 251-273.

[8] K. Piaskowski, R. Świderska-Dąbrowska, and P.K. Zarzycki, Dye Removal from Water and Wastewater Using Various Physical, Chemical, and Biological Processes, Journal of AOAC INTERNATIONAL 101(5) (2018) 1371-1384. 
[9] A. Gürses, M. Açıkyıldız, K. Güneş, and M.S. Gürses, Dyes and Pigments: Their Structure and Properties, in Dyes and Pigments. 2016. p. 13-29.

[10] M. Shabbir, Textiles and Clothing. 2019.

[11] K. He, G. Chen, G. Zeng, A. Chen, Z. Huang, J. Shi, M. Peng, T. Huang, and L. Hu, Enhanced removal performance for methylene blue by kaolin with graphene oxide modification, Journal of the Taiwan Institute of Chemical Engineers 89(2018) 77-85.

[12] R. Khan, P. Bhawana, and M.H. Fulekar, Microbial decolorization and degradation of synthetic dyes: a review, Reviews in Environmental Science and Bio/Technology 12(1) (2012) 75-97.

[13] R. Sabarish and G. Unnikrishnan, Polyvinyl alcohol/carboxymethyl cellulose/ZSM-5 zeolite biocomposite membranes for dye adsorption applications, Carbohydrate Polymers 199(2018) 129-140.

[14] S. Radoor, J. Karayil, A. Jayakumar, J. Parameswaranpillai, and S. Siengchin, An efficient removal of malachite green dye from aqueous environment using ZSM-5 zeolite/polyvinyl alcohol/carboxymethyl cellulose/sodium alginate bio composite, Journal of Polymers and the Environment 29(7) (2021) 2126-2139.

[15] S. Radoor, J. Karayil, J. Parameswaranpillai, and S. Siengchin, Adsorption Study of Anionic Dye, Eriochrome Black T from Aqueous Medium Using Polyvinyl Alcohol/Starch/ZSM-5 Zeolite Membrane, Journal of Polymers and the Environment 28(10) (2020) 2631-2643.

[16] M.-X. Zhu, L. Lee, H.-H. Wang, and Z. Wang, Removal of an anionic dye by adsorption/precipitation processes using alkaline white mud, Journal of Hazardous Materials 149(3) (2007) 735-741.

[17] H. Yi, D. Huang, L. Qin, G. Zeng, C. Lai, M. Cheng, S. Ye, B. Song, X. Ren, and X. Guo, Selective prepared carbon nanomaterials for advanced photocatalytic application in environmental pollutant treatment and hydrogen production, Applied Catalysis B: Environmental 239(2018) 408-424.

[18] D. Xu, B. Cheng, S. Cao, and J. Yu, Enhanced photocatalytic activity and stability of Z-scheme Ag2CrO4-GO composite photocatalysts for organic pollutant degradation, Applied Catalysis B: Environmental 164(2015) 380-388.

[19] S. Radoor, J. Karayil, J. Parameswaranpillai, and S. Siengchin, Removal of anionic dye Congo red from aqueous environment using polyvinyl alcohol/sodium alginate/ZSM-5 zeolite membrane, Scientific Reports 10(1) (2020).

[20] R. Sabarish, K. Jasila, J. Aswathy, P. Jyotishkumar, and S. Suchart, Fabrication of PVA/agar/modified ZSM-5 zeolite membrane for removal of anionic dye from aqueous solution, International Journal of Environmental Science and Technology 18(9) (2020) 25712586.

[21] S.M. Anush, H.R. Chandan, and B. Vishalakshi, Synthesis and metal ion adsorption characteristics of graphene oxide incorporated chitosan Schiff base, International Journal of Biological Macromolecules 126(2019) 908-916.

[22] S. Moosavi, C.W. Lai, S. Gan, G. Zamiri, O. Akbarzadeh Pivehzhani, and M.R. Johan, Application of Efficient Magnetic Particles and Activated Carbon for Dye Removal from Wastewater, ACS Omega 5(33) (2020) 20684-20697.

[23] S. Radoor, J. Karayil, J. Parameswaranpillai, and S. Siengchin, Adsorption of methylene blue dye from aqueous solution by a novel PVA/CMC/halloysite nanoclay bio composite: Characterization, kinetics, isotherm and antibacterial properties, Journal of Environmental Health Science and Engineering 18(2) (2020) 1311-1327.

[24] T. Huang, M. Yan, K. He, Z. Huang, G. Zeng, A. Chen, M. Peng, H. Li, L. Yuan, and G. Chen, Efficient removal of methylene blue from aqueous solutions using magnetic graphene oxide modified zeolite, Journal of Colloid and Interface Science 543(2019) 43-51.

[25] S.M. Anush, H.R. Chandan, B.H. Gayathri, Asma, N. Manju, B. Vishalakshi, and B. Kalluraya, Graphene oxide functionalized chitosan-magnetite nanocomposite for removal of $\mathrm{Cu}(\mathrm{II})$ and $\mathrm{Cr}(\mathrm{VI})$ from waste water, International Journal of Biological Macromolecules 164(2020) 43914402. 
[26] S. Radoor, J. Karayil, A. Jayakumar, J. Parameswaranpillai, and S. Siengchin, Removal of Methylene Blue Dye from Aqueous Solution using PDADMAC Modified ZSM-5 Zeolite as a Novel Adsorbent, Journal of Polymers and the Environment 29(10) (2021) 3185-3198.

[27] R. Sabarish and G. Unnikrishnan, A novel anionic surfactant as template for the development of hierarchical ZSM-5 zeolite and its catalytic performance, Journal of Porous Materials 27(3) (2020) 691-700.

[28] S. Radoor, J. Karayil, A. Jayakumar, J. Parameswaranpillai, and S. Siengchin, Efficient removal of methyl orange from aqueous solution using mesoporous ZSM-5 zeolite: Synthesis, kinetics and isotherm studies, Colloids and Surfaces A: Physicochemical and Engineering Aspects 611(2021).

[29] R. Sabarish and G. Unnikrishnan, Synthesis, characterization and evaluations of micro/mesoporous ZSM-5 zeolite using starch as bio template, SN Applied Sciences 1(9) (2019).

[30] R. Sabarish and G. Unnikrishnan, Novel biopolymer templated hierarchical silicalite-1 as an adsorbent for the removal of rhodamine B, Journal of Molecular Liquids 272(2018) 919-929.

[31] R. Sabarish and G. Unnikrishnan, Synthesis, characterization and catalytic activity of hierarchical ZSM-5 templated by carboxymethyl cellulose, Powder Technology 320(2017) 412-419.

[32] Wojciechowska, Król, Bajda, and Mozgawa, Sorption of Heavy Metal Cations on Mesoporous ZSM5 and Mordenite Zeolites, Materials 12(19) (2019).

[33] R. Sabarish and G. Unnikrishnan, PVA/PDADMAC/ZSM-5 zeolite hybrid matrix membranes for dye adsorption: Fabrication, characterization, adsorption, kinetics and antimicrobial properties, Journal of Environmental Chemical Engineering 6(4) (2018) 3860-3873.

[34] U. Habiba, T.A. Siddique, T.C. Joo, A. Salleh, B.C. Ang, and A.M. Afifi, Synthesis of chitosan/polyvinyl alcohol/zeolite composite for removal of methyl orange, Congo red and chromium(VI) by flocculation/adsorption, Carbohydrate Polymers 157(2017) 1568-1576.

[35] U. Habiba, T.A. Siddique, J.J. Li Lee, T.C. Joo, B.C. Ang, and A.M. Afifi, Adsorption study of methyl orange by chitosan/polyvinyl alcohol/zeolite electrospun composite nanofibrous membrane, Carbohydrate Polymers 191(2018) 79-85.

[36] B. Baheri, R. Ghahremani, M. Peydayesh, M. Shahverdi, and T. Mohammadi, Dye removal using 4A-zeolite/polyvinyl alcohol mixed matrix membrane adsorbents: preparation, characterization, adsorption, kinetics, and thermodynamics, Research on Chemical Intermediates 42(6) (2015) 5309-5328.

[37] M.S. Shamsudin, S.F. Azha, M. Shahadat, and S. Ismail, Cellulose/bentonite-zeolite composite adsorbent material coating for treatment of $\mathrm{N}$-based antiseptic cationic dye from water, Journal of Water Process Engineering 29(2019).

[38] C.V. Prasad, B.Y. Swamy, H. Sudhakar, T. Sobharani, K. Sudhakar, M.C.S. Subha, and K.C. Rao, Preparation and characterization of $4 \mathrm{~A}$ zeolite-filled mixed matrix membranes for pervaporation dehydration of isopropyl alcohol, Journal of Applied Polymer Science 121(3) (2011) 1521-1529.

[39] C.V. Prasad, B. Yeriswamy, H. Sudhakar, P. Sudhakara, M.C.S. Subha, J.I. Song, and K.C. Rao, Preparation and characterization of nanoparticle-filled, mixed-matrix membranes for the pervaporation dehydration of isopropyl alcohol, Journal of Applied Polymer Science 125(5) (2012) 3351-3360.

[40] S. Narayanan, J.J. Vijaya, S. Sivasanker, C. Ragupathi, T.M. Sankaranarayanan, and L.J. Kennedy, Hierarchical ZSM-5 catalytic performance evaluated in the selective oxidation of styrene to benzaldehyde using TBHP, Journal of Porous Materials 23(3) (2016) 741-752.

[41] P. Bai, P. Wu, W. Xing, D. Liu, L. Zhao, Y. Wang, B. Xu, Z. Yan, and X.S. Zhao, Synthesis and catalytic properties of ZSM-5 zeolite with hierarchical pores prepared in the presence of $n$ hexyltrimethylammonium bromide, Journal of Materials Chemistry A 3(36) (2015) 1858618597. 
[42] S.B. Teli, M. Calle, and N. Li, Poly(vinyl alcohol)-H-ZSM-5 zeolite mixed matrix membranes for pervaporation separation of methanol-benzene mixture, Journal of Membrane Science 371(1-2) (2011) 171-178.

[43] M. Amirilargani and B. Sadatnia, Poly(vinyl alcohol)/zeolitic imidazolate frameworks (ZIF-8) mixed matrix membranes for pervaporation dehydration of isopropanol, Journal of Membrane Science 469(2014) 1-10.

[44] X. Fan, L. Yu, L. Li, C. Yang, J. Wen, X. Ye, J. Cheng, and Y. Hu, Characterization and application of zeolitic imidazolate framework-8@polyvinyl alcohol nanofibers mats prepared by electrospinning, Materials Research Express 4(2) (2017).

[45] R.S. Veerapur, M.B. Patil, K.B. Gudasi, and T.M. Aminabhavi, Poly(vinyl alcohol)-zeolite T mixed matrix composite membranes for pervaporation separation of water+1,4-dioxane mixtures, Separation and Purification Technology 58(3) (2008) 377-385.

[46] E. Alver and A.Ü. Metin, Anionic dye removal from aqueous solutions using modified zeolite: Adsorption kinetics and isotherm studies, Chemical Engineering Journal 200-202(2012) 5967.

[47] S. Liu, Y. Ding, P. Li, K. Diao, X. Tan, F. Lei, Y. Zhan, Q. Li, B. Huang, and Z. Huang, Adsorption of the anionic dye Congo red from aqueous solution onto natural zeolites modified with $\mathrm{N}, \mathrm{N}$ dimethyl dehydroabietylamine oxide, Chemical Engineering Journal 248(2014) 135-144.

[48] V. Vimonses, S. Lei, B. Jin, C.W.K. Chow, and C. Saint, Kinetic study and equilibrium isotherm analysis of Congo Red adsorption by clay materials, Chemical Engineering Journal 148(2-3) (2009) 354-364.

[49] Y. Liu, Y. Zheng, and A. Wang, Enhanced adsorption of Methylene Blue from aqueous solution by chitosan-g-poly (acrylic acid)/vermiculite hydrogel composites, Journal of Environmental Sciences 22(4) (2010) 486-493.

[50] R. Han, J. Zhang, P. Han, Y. Wang, Z. Zhao, and M. Tang, Study of equilibrium, kinetic and thermodynamic parameters about methylene blue adsorption onto natural zeolite, Chemical Engineering Journal 145(3) (2009) 496-504.

[51] S. Sohrabnezhad and A. Pourahmad, Comparison absorption of new methylene blue dye in zeolite and nanocrystal zeolite, Desalination 256(1-3) (2010) 84-89.

[52] B.A. Fil, C. Ozmetin, and M. Korkmaz, Cationic Dye (Methylene Blue) Removal from Aqueous Solution by Montmorillonite, Bulletin of the Korean Chemical Society 33(10) (2012) 31843190.

[53] L. Zhang, H. Zhang, W. Guo, and Y. Tian, Removal of malachite green and crystal violet cationic dyes from aqueous solution using activated sintering process red mud, Applied Clay Science 93-94(2014) 85-93.

[54] M. Foroughi-Dahr, H. Abolghasemi, M. Esmaili, A. Shojamoradi, and H. Fatoorehchi, Adsorption Characteristics of Congo Red from Aqueous Solution onto Tea Waste, Chemical Engineering Communications 202(2) (2014) 181-193.

[55] V.S. Mane and P.V. Vijay Babu, Kinetic and equilibrium studies on the removal of Congo red from aqueous solution using Eucalyptus wood (Eucalyptus globulus) saw dust, Journal of the Taiwan Institute of Chemical Engineers 44(1) (2013) 81-88.

[56] I.A.W. Tan, B.H. Hameed, and A.L. Ahmad, Equilibrium and kinetic studies on basic dye adsorption by oil palm fibre activated carbon, Chemical Engineering Journal 127(1-3) (2007) 111-119.

[57] K.Y. Hor, J.M.C. Chee, M.N. Chong, B. Jin, C. Saint, P.E. Poh, and R. Aryal, Evaluation of physicochemical methods in enhancing the adsorption performance of natural zeolite as lowcost adsorbent of methylene blue dye from wastewater, Journal of Cleaner Production 118(2016) 197-209.

[58] S. Radoor, J. Karayil, J. Parameswaranpillai, and S. Siengchin, Adsorption of methylene blue dye from aqueous solution by a novel PVA/CMC/halloysite nanoclay bio composite: Characterization, kinetics, isotherm and antibacterial properties, Journal of Environmental Health Science and Engineering (2020). 
[59] V. Vimonses, S. Lei, B. Jin, C.W.K. Chow, and C. Saint, Adsorption of congo red by three Australian kaolins, Applied Clay Science 43(3-4) (2009) 465-472. 